\title{
Presencia inadvertida de la literacidad crítica en México: ocho casos para tomarse en cuenta
}

\author{
Overseen presence of critical literacy in Mexico: \\ Eight cases to be analyzed
}

\section{Rosa MARÍA Quesada MejíA*}

Este artículo presenta ocho experiencias de trabajo pedagógico de literacidad crítica en espacios escolares públicos y privados en México. Se realizaron entrevistas y estudios de caso, y se tomaron como unidad de análisis la perspectiva y la práctica pedagógica de maestras y maestros específicos. Con base en visiones latinoamericanas de la literacidad crítica (Freire, 1970; Hernández, 2016; Hernández y Quesada, 2020), se reflexiona sobre la diferencia entre ambientes educativos donde se trabaja la literacidad y donde no se trabaja. El hallazgo central es que la literacidad crítica se da no solo en clases formales de lengua (lectura y redacción, literacidad académica), sino en cursos de otro tipo de contenido; incluso, entre docentes que no declaran trabajar de manera intencional la literacidad crítica, esta se da en su práctica pedagógica. Se concluye que la calidad de la educación sería mucho mejor si los docentes fueran conscientes de las posibilidades que les brinda un enfoque crítico en el trabajo con la literacidad y, para ello, podrían tomar como modelos las experiencias aquí presentadas.

This article presents eight experiences of critical literacy pedagogy in public and private schools in Mexico. Methodologically, case studies were carried out, employing as unit of analysis the perspective and pedagogical practice of specific teachers. Based on Latin American views on critical literacy (Freire 1970; Hernández 2016), we reflect on the difference between educational environments where critical literacy is enacted vs those in which it is not. The key finding is that critical literacy is enacted not just in formal language classes (e.g. reading and writing courses), but also in courses of diverse contents; we also found that even teachers who declare not to work with critical literacy in mind, they actually enact it in their pedagogy practice. In conclusion, the quality of education would significantly improve if the teachers developed awareness of the possibilities that a critical approach lends to literacy work, for which they could use, as a model, experiences such as those presented in this article.

\section{Palabras clave:}

pensamiento crítico, maestra modelo, competencia comunicativa

Keywords: critical thinking, model teacher, communicative competence

Recibido: 17 de junio de 2020 | Aceptado para su publicación: 26 de enero de 2021 | Publicado: 27 de febrero de 2021

Recuperado de: https://sinectica.iteso.mx/index.php/SINECTICA/article/view/1164

doi: 10.31391/S2007-7033(2021)0056-009

\footnotetext{
* Doctora en Pedagogía por la UNAM. Profesora en la Universidad Iberoamericana, campus Santa Fe, Ciudad de México.
} Líneas de investigación: cultura escrita y literatura infantil y juvenil. Correo electrónco: rosi2342@yahoo.com.mx 


\section{INTRODUCCIÓN}

\section{Por qué hablar de literacidad crítica}

$\mathrm{L}$ as oportunidades laborales actuales son mucho mayores que hace apenas algunas décadas. Ahora se puede solicitar un puesto de trabajo en cualquier lugar del mundo. Esto parece una ventaja interesante respecto a épocas anteriores. Sin embargo, el problema radica en que la competencia también es global. Los interesados provienen de países diversos y distantes, y es ahí donde los sistemas educativos de cada nación miden su verdadero valor. No solo es la capacidad de cada persona la que se pone en juego, sino el perfil de egreso general que ofrece cada sistema. En general, las personas que se atreven a aplicar a este tipo de trabajos son quienes se consideran buenas comparadas con sus compañeros de escuela, tienen buenos promedios y han ganado premios y el reconocimiento personal de sus compañeros y maestros. No obstante, al expandirse el universo de aspirantes, los resultados no suelen ser tan alentadores.

En este sentido, quienes somos maestros/as de lengua, escribimos libros de español y somos bibliotecarios/as, nos gustaría ayudar a que los resultados fueran mejores, y que el nivel general de los egresados del sistema educativo mexicano fuera más alto. Al buscar alguna forma efectiva de contribuir a lograr esta meta desde el área de la lengua, el hallazgo fue que los programas actuales proponen desarrollar alumnos constructivistas, de mente abierta y con la capacidad de resolver problemas, conscientes de su entorno y dispuestos a encontrar soluciones que aquejan al mundo (SEP, 2018, p. 3). Entonces, ¿qué papel juega la literacidad crítica en el logro de este objetivo? ¿Funciona, se aplica? ¿Quién y cómo se está trabajando en la literacidad crítica y con qué resultados? Más concretamente, ¿cómo influye el nivel de literacidad crítica de un estudiante para que se titule de su carrera? ¿Qué están haciendo los docentes para que este nivel sea el óptimo en México?

\section{Qué entendemos por literacidad crítica}

Según el Fondo de las Naciones Unidas para la Infancia (Unicef, 2019),

el efecto multiplicador de la literacidad empodera a las personas, las habilita para participar totalmente en la sociedad y contribuye a mejorar la calidad de vida. La literacidad es también una vía para el desarrollo sostenible pues habilita para una mayor participación en el mercado laboral, mejora la salud y la nutrición de los niños y sus familias y reduce la pobreza a la vez que expande las oportunidades en la vida (p. 3).

Una de las razones para que esto suceda es, primeramente, que la literacidad influye en los docentes:

El activista crítico, en la enseñanza o en cualquier otro lugar, examina también su propia práctica, no se acepta como preparado y acabado, y se reinventa en la medida en que reinventa la sociedad [...]. Nosotros nos renovamos con los estudiantes [...] el proceso iluminador renueva al educador. Si él sólo lleva la iluminación al aula de clase, el profesor puede agotarse fácilmente. La militancia significa recreación permanente [...]. El proceso liberador no es tan sólo un crecimiento profesional: es una transformación al mismo tiempo social y de uno mismo, un momento en el que aprender y cambiar a la sociedad caminan juntos (Shor, citado en Freire, 2008, p. 85). 
En otras palabras, quienes han decidido trabajar críticamente no se asumen como "los que saben" frente a un grupo formado por los "que ignoran"; son conscientes de que siguen, como todo ser humano, en constante aprendizaje y transformación. Esta visión sobre lo que significa ser educador permite que los alumnos se expresen, tomen también el rol de enseñante y se sientan más responsables de lo que sucede en el aula y con el proceso. Esta forma de dirigir un grupo afecta la manera en que los alumnos se acercan a los textos, los comprenden y se apropian de ellos.

Si nos vamos a los orígenes, recordaremos que primero se hablaba de "alfabetización crítica" antes que se acuñara el término de literacidad. Freire (1970) se refiere a ella como una "educación problematizadora" en contraste con una "educación bancaria" (p. 69). También la menciona como "leer el mundo" (Freire, 1970, p. 108) y como "procurar en el [alumno] un proceso de concienciación, o sea, de liberación de su conciencia con vistas a su posterior integración en su realidad nacional, como sujeto de su historia y de la historia" (Barreiro, citado en Freire, 2011, p. 14).

Hernández (2016) añade: "Trabajar los procesos de lectura y escritura desde una literacidad crítica implica desarrollar la capacidad para evaluar críticamente las ideas propias y ajenas, de plantear preguntas vitales, identificar y resolver problemas, utilizar y criticar fuentes, elaborar ideas y argumentos, y comunicar esas ideas en forma clara y efectiva" (p. 20) y lo refrenda:

El papel de la educación letrada (literacidad académica o pensamiento mediado por lo escrito) es justo formar mentes pensantes y críticas que intervengan en cualquier campo [...] no sólo como espectadores sino como agentes transformadores de las realidades sociales, que a la fecha plantean retos y problemáticas diversas (Hernández y Quesada, 2020, p. 41).

Cassany (2006) nos ofrece una explicación a través del contraste:

La literacidad crítica trasciende la comprensión del texto (leer las líneas); significa además leer entre líneas (deducir las palabras, aunque o se hayan dicho explícitamente, inferir, presuponer, encontrar los dobles sentidos, etc.), pero sobre todo leer detrás de las líneas (la ideología, el punto de vista la intención y la argumentación que apunta el autor) para después asumir una postura propia y actuar en consecuencia (p. 52).

Por su parte, Vázquez (2017) se refiere a la literacidad crítica como

una forma de ser [...] [que] no debe ser un complemento sino un marco a través del cual participar en el mundo dentro y fuera de la escuela. Tal marco no implica necesariamente adoptar una postura negativa; más bien, significa mirar un tema o tema de diferentes maneras, analizarlo y ser capaz de sugerir posibilidades de cambio y mejora. En este sentido, las alfabetizaciones críticas pueden ser placenteras y transformadoras, así como pedagógicas y transgresoras.

Con base en lo anterior, en este trabajo entendemos por literacidad crítica el proceso por el cual la lectura de textos ayuda al lector a transformarse y a transformar el mundo.

\section{METODOLOGíA: INDAGANDO EN LA REALIDAD}

\section{Instrumentos y sujetos de investigación}

Para responder a las preguntas guía de nuestra investigación, realizamos tres entrevistas en profundidad a tres expertos en la materia, maestros de lengua y redacción, 
nivel medio superior y superior, a fin de conocer la situación de los alumnos en estos grados. Elegimos docentes con más de veinte años de servicio, recomendadas por sus jefes inmediatos y cuyos resultados en sus alumnos se han visto reflejados en altos promedios y en la calidad de sus trabajos recepcionales que han obtenido varios galardones. Seleccionamos docentes de escuelas públicas de la Ciudad de México y del Estado de México.

Tabla 1. Sujetos de entrevista

\begin{tabular}{|c|c|c|c|}
\hline Seudónimo del docente & Materia que imparte & Centro escolar & Ubicación \\
\hline Susana & Español, historia y ética & $\begin{array}{l}\text { Preparatoria incorporada a } \\
\text { la UNAM ubicada en el norte } \\
\text { de la Ciudad de México }\end{array}$ & $\begin{array}{l}\text { Insurgentes Norte, barrio } \\
\text { popular }\end{array}$ \\
\hline Ana & $\begin{array}{c}\text { Redacción a alumnos de } \\
\text { diseño } \\
\text { Literatura }\end{array}$ & $\begin{array}{l}\text { Escuela pública de diseño } \\
\text { Bachillerato bilingüe } \\
\text { privado }\end{array}$ & $\begin{array}{c}\text { Centro de la Ciudad de } \\
\text { México } \\
\text { Norte de la ciudad, colonia } \\
\text { de clase media }\end{array}$ \\
\hline Aurora & $\begin{array}{l}\text { Prácticas escolares } \\
\text { Literatura infantil }\end{array}$ & Escuela normal estatal & $\begin{array}{l}\text { Zumpango, Estado de } \\
\text { México }\end{array}$ \\
\hline
\end{tabular}

Tras haber conocido las respuestas de estas docentes y observar un ambiente poco fecundo para el desarrollo de la literacidad crítica en los alumnos de educación media superior y superior y, por lo tanto, ver lejana la posibilidad de que, al egresar de la universidad, cuenten con los requisitos necesarios para competir a nivel internacional, decidimos indagar y encontrar propuestas en los niveles inferiores que dotaran a los estudiantes de herramientas suficientes para que desarrollaran su literacidad crítica de manera mucho más autónoma en los niveles superiores, cuando es necesario dominarla ya para avanzar académicamente, como se tiene estipulado en el currículo universitario.

Para ello, recurrimos al estudio de caso de cinco docentes de muy diversa índole, tanto por su área de trabajo como por sus actividades, objetivos y contenidos disciplinares. Son docentes de educación básica, media, media superior y de educación no escolarizada, que fueron seleccionadas porque sus ex alumnos habían sido reconocidos por profesores de educación superior como alumnos excepcionales en sus clases. En este caso, elegimos profesores que no fueran de lengua, pero que practicaran la literacidad crítica dentro de su disciplina; esto, para evidenciar que su uso no se circunscribe a las materias que tienen que ver con el uso de la lengua en específico.

Tabla 2. Sujetos de los estudios de caso

\begin{tabular}{|c|c|c|c|c|}
\hline $\begin{array}{c}\text { Seudónimo } \\
\text { del docente }\end{array}$ & Nombre del caso & $\begin{array}{c}\text { Materia que } \\
\text { imparte }\end{array}$ & $\begin{array}{c}\text { Descripción del centro } \\
\text { escolar }\end{array}$ & Ubicación \\
\hline Armando & $\begin{array}{c}\text { Maller de redacción } \\
\text { Sociología } \\
\text { verso }\end{array}$ & $\begin{array}{c}\text { Colegio de Bachilleres } \\
\text { Análisis político de } \\
\text { ideologías }\end{array}$ & $\begin{array}{c}\text { Xochimilco, al sur de la } \\
\text { Ciudad de México } \\
\text { Xochimilco }\end{array}$ \\
\hline Elena & $\begin{array}{c}\text { Gustav Klimt en la } \\
\text { biblioteca }\end{array}$ & $\begin{array}{c}\text { Arte en la } \\
\text { biblioteca }\end{array}$ & $\begin{array}{c}\text { Escuela privada bilingüe } \\
\text { para alumnos de alto } \\
\text { poder adquisitivo }\end{array}$ & $\begin{array}{c}\text { Poniente de la Ciudad de } \\
\text { México }\end{array}$ \\
\hline Edith & Sentipensarnos & Poesía & $\begin{array}{c}\text { Organización no } \\
\text { gubernamental de } \\
\text { fomento a la lectura }\end{array}$ & $\begin{array}{c}\text { Colonia Mixcoac, al } \\
\text { sur-poniente de la } \\
\text { Ciudad de México }\end{array}$ \\
\hline
\end{tabular}




\begin{tabular}{|c|c|c|c|c|}
\hline Clara & $\begin{array}{c}\text { Escribir desde } \\
\text { nuestros corazones } \\
\text { ancestrales }\end{array}$ & $\begin{array}{c}\text { Proyecto escolar } \\
\text { general }\end{array}$ & $\begin{array}{c}\text { Escuela Montessori } \\
\text { privada }\end{array}$ & Cuautla, Morelos \\
\hline Rosalía & $\begin{array}{c}\text { ¿Libertad de cáte- } \\
\text { dra? }\end{array}$ & $\begin{array}{c}\text { Metodología de la } \\
\text { investigación }\end{array}$ & $\begin{array}{c}\text { Preparatoria privada con } \\
\text { muchas sucursales } \\
\text { Preparatoria privada de } \\
\text { prestigio y alto costo }\end{array}$ & $\begin{array}{c}\text { Colonia Roma, centro de } \\
\text { la Ciudad de México } \\
\text { Lerma, Estado de México }\end{array}$ \\
\hline
\end{tabular}

\section{ENTREVISTAS}

Presentamos las tres entrevistas a maestras vinculadas estrechamente a la enseñanza de la lengua para conocer sus puntos de vista respecto al uso de la literacidad crítica dentro del aula. Con ello pretendemos lograr una mirada directa a la realidad actual, sin intermediarios o interpretaciones.

\section{Entrevista 1. Susana}

Las mayores necesidades de mis alumnos, en el sentido humano, son: motivación, ser escuchados, y aprendizaje emocional. En el sentido académico, desarrollar sus competencias lectoras, fomentar la escritura, la expresión oral. Para ayudarlos, cuento con lecturas, ficheros, secuencias didácticas y técnicas Freinet.

Sobre su literacidad crítica, en primer lugar, por cuenta propia leen muy poco; algunos de ellos tienen dificultades para leer con fluidez y claridad. Y ya ni hablar de las interpretaciones que puedan hacer sobre ellas; son verdaderamente pobres. Otros cuentan con malas experiencias de lectura (obligatoria) y se convierte en algo aburrido en automático para ellos. Por estas razones trato de llevar lecturas cortas; para el caso de historia son artículos de revistas, poemas, frases, folletos o capítulos de libros relacionados con los temas. En el caso de Formación cívica y ética, son artículos de periódicos, revistas, libros ilustrados, biografías y cuentos.

De dos ciclos anteriores a la fecha, los estudiantes presentan muchas dificultades en la lectura; algunos de ellos todavía deletrean y otros tienen dificultad para entender lo que están leyendo; en general, existe muy poco interés por la lectura.

En el caso de la escritura, los estudiantes están acostumbrados a redactar solo para cumplir, pensando que nadie los va a leer o cuestionar sobre su texto. En este caso, el uso de las técnicas Freinet son muy oportunas, porque les permite darse cuenta de la importancia de las palabras; por supuesto, que tienen muchos errores, pero la idea es equivocarse para mejorar. Trato también de hacer un acompañamiento en la lectura; esto lleva más tiempo y requiere diseñar estrategias que combinen la lectura con el desarrollo del tema. Tengo más de cien alumnos, lo cual dificulta tener una docencia personalizada, pero les hago comentarios generales esperando que les ayude a muchos a la vez.

Mucho del material empleado con los estudiantes es mío, como las revistas, folletos, libros, adquiridos en ferias del libro, museos o recomendaciones de otros compañeros. Los libros de biblioteca de aula son muy buenos materiales y pueden servir de mucho si se les sabe utilizar. Por ejemplo, cuando empezaron a llegar los acervos para las bibliotecas escolares, la subdirectora que se encontraba en ese momento nos invitó a formar un círculo de lectura a fin de conocer el acervo bibliográfico que estaba llegando a la escuela, con la intención de promocionarlo con nuestros estudiantes y compañeros. En ese momento contábamos con salones fijos y se tenían los libros a la vista de los estudiantes, realizando préstamo a domicilio e invitando a los mismos estudiantes a compartir su experiencia de lectura con sus compañeros. Fue una grata experiencia, por la convivencia generada con los compañeros y estudiantes, pero sobre todo por la 
cantidad de estudiantes que leyeron por gusto y no por obligación. Impulsó a varios de nosotros a escribir sobre nuestras experiencias de enseñanza-aprendizaje llevadas a cabo con nuestros estudiantes. Desafortunadamente, en muchas escuelas no existe una organización que permita tener a mano los materiales.

Considero, por otro lado, que una de nuestras más grandes debilidades es que la literacidad de mis colegas profesores no es su fuerte. Para ejemplificar está situación, comparto dos anécdotas que dan cuenta de ello:

- En una reunión de consejo técnico muchos profesores estábamos inconformes por la forma de conducirse del director en algunas situaciones que se habían dado en la escuela. En la reunión se le expusieron al director, sin obtener la respuesta esperada. Posteriormente, vino una discusión para elaborar por escrito las inconformidades y hacerlas llegar a la autoridad superior. En esa reunión, las profesoras de la asignatura de español se habían retirado a un curso y, a pesar del enojo generado por la respuesta del director, ninguno de nosotros quiso realizar el escrito, argumentando que esa redacción debían hacerla las profesoras de español.

- Para no perder la costumbre, en otra junta de Consejo Técnico, la supervisora fue la encargada de llevar a cabo la sesión debido a que no teníamos director. Para ello, hizo una presentación en PowerPoint; al cabo de unas cuantas diapositivas, pidió el apoyo para seguir con la lectura y muchos compañeros empezaron con un listado de pretextos para no leer.

\section{Entrevista 2. Ana}

Los principales retos como maestra de lengua y redacción son interesar a los alumnos en la lectura y en el conocimiento en general y conectar con gente mucho más joven que yo.

Las más grandes necesidades académicas de mis alumnos son comprensión lectora, pensamiento crítico, expresión oral y escrita. De otros tipos: atención, afecto. Lo bueno es que cuento en la escuela pública con estudiantes creativos y dispuestos, buenos textos (aunque ni siquiera tienen biblioteca ni internet) y en la privada con estudiantes ñoños [sic] y responsables, internet para videos como los TED (cuando funciona), un foro padre (teatro), biblioteca. La cantidad de lectura varía, pero, en general, en la escuela privada leen cuatro libros en un año escolar, en mi clase. Y por lo menos uno más en sus otras clases. Hay algunos lectores ávidos, que hicieron el hábito desde más chicos. Por ejemplo, en el tema de hermenéutica leen como seis cuentos y cuatro o cinco poemas, tal vez una obra de teatro; en teatro leen por lo menos dos obras; en ética leemos uno y en las otras, algunos artículos. Algunos empiezan sin comprender nada, pero como el enfoque de la materia es justo eso, la mayoría termina siendo capaz de comprender ironías, hacer inferencias, captar simbolismos. En la escuela de diseño, solo sé que leen entre ocho y diez artículos sobre diseño al semestre, en distintas materias. Depende de la optativa que elijan, algunos leen más. Ahí hay muchos grados distintos de comprensión lectora entre los alumnos, pero como hay un proceso de selección riguroso, en general, son chicos listos, que saben leer bien aunque no se interesen por la ficción, por ejemplo.

Leemos todo el tiempo, pero, en general, leo justamente con ellos. No lo dejo de tarea.

Sobre escritura, en la escuela privada escriben unos seis textos al año escolar en clase de Lectura y su calidad varía mucho en tanto a redacción, el idioma y su profundidad o creatividad.

En la de diseño los leo poco. En general, buscan la seguridad del lenguaje académico (un poco falsamente rimbombante y repetitivo) porque algunos profes se lo exigen así.

Cuando di la materia Argumentación en la maestría, los textos finales que lograban escribir eran muy buenos. 
En la escuela privada los alumnos tienen posibilidad de comprar muchos libros, pero no sé si haya interés, en todos los casos. En la escuela de educación superior, en muchos casos, es un reto económico que puedan conseguir libros y además no dominan otro idioma para leer textos extranjeros; pero casi todos son muy hábiles en el manejo de la tecnología digital y encuentra cosas increíbles en la red.

Considero que las prácticas de lectura y escritura deberían de ser una de sus competencias principales, porque les hace acercarse a las otras materias, desde un lugar de mayor confianza y claridad, pero no depende de mí y no creo que tampoco de los otros profes de educación superior, sino de sus estudios previos y las materias optativas que decidan cursar. Creo que las diferencias en el nivel de competencia en comprensión escrita entre mis alumnos se deben a sus experiencias previas con la lectura en la educación básica y su cultura familiar lectora.

\section{Entrevista 3. Aurora}

Esta maestra de maestras, por iniciativa propia, desarrolló la materia de literatura infantil y montó una biblioteca infantil dentro de la Escuela Normal, a la que nombró "El cuaderno de Pancha" (como el libro), necesaria para impartir la clase. A continuación, presentamos lo que opina sobre la cultura escrita y la literacidad crítica:

Con el grupo de la sala de literatura participamos en eventos de lectura del municipio en las ferias y eventos de fechas especiales. Yo los pongo a organizarlas y les hago ver que si ellos no se entusiasman con la lectura, no podrán entusiasmar a los demás. Esto lo utilizo de gancho y estos maestros en ciernes, todavía con muchos ideales, se ponen a estudiar y leer con tal de poder compartir con los otros sus conocimientos.

En cuanto a las bibliotecas, la general tiene un acervo suficiente, pero está mal clasificado, es difícil encontrar los libros y muchos no los regresan. Muy pocos alumnos acuden a buscar libros. Los que van lo hacen porque hay internet gratis. Esa biblioteca es muy pobre. Y está, por supuesto, la sala de literatura infantil y juvenil "El cuaderno de Pancha". Está muy bonita, tiene un amplio acervo especializado y está bien acondicionada, pero no tiene un buen sistema de préstamo, por lo que muchos libros se están perdiendo. No hay bibliotecaria que pueda llevar un control bien administrado. Creo que si no hay alguien en estos espacios que oriente, los materiales no surten efecto solos.

Por su parte, lo que puedo decir de mis colegas profesores es que la mayoría son comprometidos con su trabajo, pero muy pocos son propositivos, creadores, con iniciativa, investigadores, preocupados verdaderamente por sus alumnos.

\section{Análisis de las entrevistas}

En las entrevistas observamos diversas ideas y acciones pedagógicas interesantes, algunas plausibles y algunas coartadas por el contexto y las circunstancias generales. Por razones de espacio, nos enfocaremos en cuatro puntos relevantes sobre la literacidad crítica que están presentes en el trabajo de estas maestras:

- Es necesario tener un acercamiento personal con los alumnos para lograrlo. El exceso de alumnado sobrepasa las capacidades de cualquier maestro para ser empático y encontrar soluciones adecuadas para cada caso.

- Existen técnicas que se pueden utilizar para desarrollar la literacidad crítica; no es necesario "inventarlo" todo; ejemplo: las técnicas Freinet. 
- El trabajo que trasciende a las aulas es siempre un buen aliciente para que exista un compromiso personal y significativo con el aprendizaje. Es lo que se puede observar en el trabajo de Aurora, quien diseña a partir de lo que los alumnos pueden aportar a su comunidad, y no deja su currículo aislado y en una burbuja escolar.

- Los alumnos traen conocimientos previos externos que les permiten hacer conexiones, o no. Es necesario tomar en cuenta el contexto donde viven los alumnos para subsanar las carencias y aprovechar las experiencias con las que llegan al aula; nunca obviarlas ni hacer caso omiso de ellas.

También advertimos dos grandes limitaciones que se repiten en todos los casos:

"La falta de interés de "los otros docentes" por la literacidad de sus alumnos. Esto debilita la posibilidad de trabajar las experiencias de literacidad desde muchos ángulos y momentos. Pareciera que la literacidad crítica es "asunto del maestro de lengua".

- La falta de recursos accesibles para todos siempre. Incluso, la maestra Ana hace mención que los recursos digitales pueden llegar a fallar incluso en la escuela privada.

\section{BUENAS PRÁCTICAS: CASOS MODELO DEL DESARROLLO DE LA LITERACIDAD CRÍTICA}

A partir de leer y analizar las entrevistas, decidimos presentar cinco ejemplos de maestros que han trabajado con la literacidad crítica como el enfoque que sustenta su trabajo. Ellos no han empleado grandes presupuestos ni transformaciones de los planes y programas y, sin embargo, han creado ambientes de literacidad crítica en los que los alumnos logran conocerse, asumirse, construirse y plantarse frente al mundo con una postura firme y definida, en aras de transformarlo y mejorarlo. Sus ex alumnos han demostrado poseer competencias que otros estudiantes no tienen. Al evidenciar estas experiencias favorables, pretendemos mostrar cómo el uso de una literacidad crítica en el aula puede hacer una diferencia en los resultados académicos globales de los estudiantes.

\section{Mi lugar en el universo}

Armando trabaja con alumnos de primer semestre de licenciatura y de bachillerato. La estrategia que nos compartió fue la de inicio de cursos, cuya finalidad es convencer a los alumnos que el estudio impacta no solo en el conocimiento, sino en su propia identidad. El trabajo consiste en hacerlos conscientes de que su universo incluye más allá de su hogar y su pequeña escuela. Su tarea como universitarios es darse cuenta de que lo que hay que conocer es mucho más amplio que lo que está a cinco metros de distancia, y que tienen la posibilidad y hasta la responsabilidad de explorarlo en su totalidad.

Una de sus dinámicas consiste en poner una línea del tiempo en el pizarrón y explicar que si la existencia del universo fuera de un año, la del Homo sapiens solo abarcaría los últimos cinco minutos del último día. Luego, les hace ver que nuestra 
dimensión es también muy relativa: ¿somos grandes, somos minúsculos? La respuesta depende de si uno se compara con los microuniversos que existen dentro de una simple célula o con los megauniversos que hay fuera de este en el que vivimos. Se apoya en videos de Carl Sagan y Neil de Grasse Tyson (2019) sobre la historia de la modernidad.

Sentirse parte de un sistema, un engrane que embona perfectamente en este mecanismo, da sentido a la vida y lo ubica a uno al otorgar una sensación de pertenencia. Cuando una persona se da cuenta de que su vida es parte de un continuo histórico y que sus acciones repercuten en el desarrollo global del mundo, el valor personal se eleva y se dignifica.

Las razones para tomarse el tiempo y concienciar a los estudiantes sobre su sentido histórico dentro de una clase de literacidad, o de cultura, o de otra materia, son las siguientes:

Para introducir a los alumnos en la literacidad académica, se deben socializar las prácticas discursivas, que implican tres aspectos centrales:

- La escritura académica, que es el medio fundamental para construir y crear conocimiento.

- Los comportamientos letrados, que se resumen en desarrollar la capacidad de dar explicaciones ordenadas, interpretaciones fundamentadas, argumentos lógicos y análisis abstractos.

- Pensamiento crítico, que consiste en desarrollar la capacidad para evaluar críticamente las ideas propias y ajenas, plantear preguntas vitales, identificar y resolver problemas, utilizar y criticar fuentes, elaborar ideas y argumentos y comunicar esas ideas de forma clara y efectiva (Hernández, 2016, p. 19).

Este ejercicio introductorio plantea preguntas vitales; la primera de ella es: ¿quién soy? El recorrido por las aulas deberá ayudar a responder a esta pregunta, y darle sentido a todo lo que se estudia, pues no solo se estudiará para memorizar información, sino para darle sentido y significado al trabajo que realizamos, a lo que estudiamos $y$, finalmente, a lo que le da sentido a nuestra vida.

El profesor afirma:

En otras palabras, se modifica tu conciencia de quién eres pues conocer tu sitio en la historia imprime una dimensión mucho más amplia de la que se tenía antes de ubicarse dentro del todo infinito del que formamos parte.

En cuanto a las "armas secretas" con las que contamos los profesores, considero que para lograr que un estudiante se interese por un tema del cual nunca había escuchado y no consideraba importante ni apelativo, es necesario utilizar material actualizado y divertido. Las buenas clases no tienen por qué utilizar material hecho sin chiste ni gracias, con voces en off desanimadas, haciendo sentir que el tema es en sí mismo un suplicio. Existen formatos bien entretenidos, que se ajustan más a los memes o tik toks a los que ellos están acostumbrados. Yo utilizo formatos distintos a los tradicionales para enseñar y para que escriban. También creo que es importante mantener una postura optimista con respecto a lo que se enseña, y siempre mostrar el lado amable o positivo, incluso cuando se hable de momentos desagradables de la historia, por ejemplo. 
Considero además que la creatividad es un elemento que no debe de faltar en una clase en donde se toca el tema de conciencia crítica. El maestro debe de intentar ser siempre innovador, pero tampoco tiene que olvidar que los alumnos tienen una gran imaginación, y sería muy benéfico para todos que en lugar de exigir formatos cuadrados e inamovibles, les permitiera jugar y expresarse a su manera.

Con estas actividades e ideas (y así lo verbaliza), este profesor muestra que su trabajo tiene como objetivo transformar a la persona, y no transmitirle el contenido del programa.

\section{Gustav Klimt en la biblioteca}

La segunda educadora, Elena, trabaja al servicio de los otros profesores de la escuela. Es bibliotecaria en una escuela incorporada al Programa de Bachillerato Internacional, una acreditación a nivel mundial que pretende estandarizar el perfil de egreso de todos los alumnos que finalizan la educación media superior. Este programa tiene el pensamiento crítico como una de sus banderas. Por tanto, la escuela -que también incluye grupos desde preescolar hasta bachillerato- se basa en la certeza de que el trabajo de investigación y, por lo tanto, de creación de conocimiento, parte de la biblioteca. Considera que esta no es tanto un centro de almacenamiento como de producción. Por ello, la encargada de la biblioteca es un personaje central dentro del sistema escolar, al apoyar a cualquier maestro, estudiante, padre de familia o administrativo que lo requiera.

Esta coordinadora del centro de información (como se le conoce a la biblioteca), además de responder a las necesidades de cada profesor, también desarrolla proyectos independientes que apoyan el pensamiento crítico, porque tiene muy claro que esa es su función: desarrollar la literacidad crítica, que va de la mano del pensamiento crítico.

El trabajo que nos presentó tiene que ver con una exposición de arte. Este proyecto ha ido creciendo a lo largo de año y medio, y ha dado siempre cada vez más. Comenzó con el pretexto de festejar el centésimo aniversario luctuoso de Gustav Klimt. Ella inició plotteando las diez obras más importantes del autor y poniendo alrededor suyo todos los libros de la biblioteca que tuvieran que ver con él, desde información biográfica hasta la situación histórica que vivía. También incluyó libros de arte sobre las técnicas utilizadas por el artista. Cuando envió la invitación a casa para que los padres fueran a ver la exposición, uno de los padres de familia le habló para decirle que él era cirujano plástico, pero pintor por vocación, y que había reproducido un cuadro de Klimt y lo quería prestar para la exposición. Fue muy interesante, porque les contó que, como él era cirujano, quiso mejorar la cara de la muchacha en el cuadro iporque la original presentaba prognatismo!

Cuando la exhibición fue abierta al público, cada salón tuvo su tiempo para visitarla y, en uno de esos recorridos, una niña comentó que no le gustaba porque a ella el dorado la hacía sentir incómoda. La bibliotecaria retomó el comentario y se le ocurrió iniciar otra ronda de visitas haciendo que la gente se centrara en el color. Recordó que en un museo que había visitado había unas urnas transparentes y unas fichas de colores junto a cada cuadro. Cada color representaba una emoción (rabia, ternura, miedo, tristeza, alegría). A los visitantes se les pidió tomar una ficha del color que representara su sentimiento y ponerla en la urna. Así, se podía reconocer de 
un vistazo a la urna cuál era la emoción que causaba el cuadro con mayor frecuencia, pues, evidentemente, el sentimiento no era cien por ciento igual.

La bibliotecaria, junto con la maestra de quinto de primaria, han continuado trabajando las emociones a través del arte; se han apoyado en sus experiencias personales y las han compartido, pues la bibliotecaria dice que ella nunca ha estado frente a grupo y que las propuestas didácticas de la maestra le han sido muy útiles para aterrizar sus ideas.

Actualmente, están experimentando con la música y las texturas para ver cómo se relacionan. La bibliotecaria comenta que "a partir del chispazo de Klimt han logrado hacer un trabajo socioemocional muy amplio, llegando hoy en día a trabajar con la toma de decisiones". Al preguntarle sobre las claves para desarrollar la literacidad crítica, contestó lo siguiente:

En primer lugar, el docente tiene que tener la intención de hacerlo, ver más allá del contenido que va a compartir y tener siempre en mente que no va a ser su trabajo el que destaque, sino el de los alumnos. En primer lugar, habrá que buscar las oportunidades de conectar el tema en cuestión con el contexto del momento para darle su lugar dentro de la vida presente de los estudiantes y de esta manera conectarlo naturalmente con él y su desarrollo, con él y su entorno. Después, habrá que buscar el detonador con el cual los alumnos inicien su indagación o su serie de preguntas e hipótesis que desean contestar. A continuación, el papel que juego es el de mediadora entre la información y el estudiante, le doy acceso y le acerco los materiales que les pueden ser útiles, ya sean libros o revistas, mapas, películas, videos, exposiciones presenciales o virtuales, lo que necesite.

El siguiente paso es socializar los conocimientos, compartir las dudas, los avances, para poder retroalimentarse con los comentarios de los demás. Esto lo hace principalmente a través de paneles, debates, pláticas con invitados expertos o testigos que platiquen su testimonio. Solo hasta ese momento siente que están preparados para escribir un reporte de lo aprendido, que puede tener cualquier modalidad, porque no solo lo presentan en textos, sino en carteles, videos o hasta memes, o en el montaje de una exposición, como fue el caso con el tema del arte contemporáneo.

Elena se expresa de su trabajo así: "Yo creo que siguiendo estos pasos estoy contribuyendo a la construcción de su literacidad crítica".

\section{Sentipensarnos}

Esta colega es una promotora de lectura free-lance que trabaja sobre todo en espacios no escolarizados con públicos diversos. La experiencia que nos compartió la realizó para una organización no gubernamental internacional cuya finalidad es fomentar la lectura. La llevó a cabo con maestros de lengua con muchos años de experiencia y que se enfocan en enseñar a redactar, a no cometer faltas de ortografía y de puntuación. Comenta que es un reto muy distinto al de su trabajo con promotores de lectura que buscan utilizar los libros de cuentos para hacer pasar un buen rato a los niños. "Los dos carecen de sentido crítico, pero desde extremos opuestos. Unos leen para 'enseñar el tema' y los otros 'para recrear'”.

En sus talleres, ella intenta demostrar que la literatura puede elevar los niveles de análisis y conciencia de los lectores, y así formar grupos solidarios que sepan hacer comunidad y vivir en paz. En otras palabras, para ella el trabajo con la literatura significa 
tener un alto grado de competencia en la literacidad crítica, que se convierte, a su vez, en un alto sentido de agencia. Su filosofía se basa en retomar las formas tradicionales de leer, pero no asumirlas de manera automática, sino evaluarlas y continuar con aquellas que aportan a la colectividad hoy, y transformar las partes que han sido rebasadas por las circunstancias actuales y mejorarlas con las nuevas ofertas. Esto lo señala hablando tanto de los contenidos de clase como de los textos literarios, así como de las metodologías de lectura: "Lo importante cuando se habla de literacidad crítica no es tanto preservar, sino evolucionar para significar".

Lejos se quedan las clases obtusas y sinsentido de listas de palabras de ortografía incomprensibles y fuera de contexto; también el estudio de los clásicos por el mero hecho de ser clásicos, y las preguntas con respuesta única. Ella propone aprender palabras en contexto, que sean necesarias para entender una situación dada, leer cualquier texto, iniciando con textos de calidad, pero de cualquier época y formato (iincluyendo cómics, por ejemplo!), y después incluso revisando otros textos no tan bien elaborados a fin de contrastar y valorar las deficiencias en unos y los aciertos en otros. Finalmente, propone siempre "colocarnos como sujetos frente a un texto y conversar con él, escuchar lo que nos dice, hacerlo resonar en nuestro interior y contestar".

Esta lectora apoya la idea de que no hay que pensar, sino senti-pensar, porque solo lo que "nos toca" se quedará con nosotros y, en el mismo sentido, está de acuerdo con darle el mismo valor heurístico al arte que a las ciencias (para aprender más al respecto, consultar los trabajos de Nussbaum, 2008). Considera que la identificación con los personajes ficticios de un texto son un elemento que favorece mucho el compenetrarse con los temas que se tratan. Para ella, cualquier texto o "tema" que se vaya a compartir tiene que ser primero parte del repertorio personal del maestro; no se puede enseñar lo que no se ama. Nos compartió un texto que a ella le ha abierto su comprensión acerca de lo que es la lectura y la escritura como experiencia:

Lo importante desde el punto de vista de la experiencia es cómo la lectura puede ayudarme a decir lo que aún no sé decir, o lo que aún no puedo decir, o lo que aún no quiero decir. Lo importante es que la lectura me ayude a transformar mis propias palabras, mi propio lenguaje, que me ayude a hablar por mí mismo, o a escribir por mí mismo, en primera persona, con mis propias palabras. Lo importante no es lo que pueda pensar sobre el libro, sino el modo como en relación con los pensamientos que leo puedo transformar mis propios pensamientos, así como mis sentimientos (Larrosa, 2003, p. 90).

La actividad que compartió fue trabajada con un libro llamado La gran pregunta, de Wolf Elbruch (2005), que es interactivo, lo cual quiere decir que requiere un lector activo y pensante. Cada página presenta un personaje distinto, como un soldado, una piedra, un pato, un ama de casa, que deben contestar a la pregunta “¿tú, para qué estás aquí?". Cada uno responde según su esencia: "Estoy aquí para durar, para obedecer, para crecer, etc.". La última página está en blanco para que sea el lector quien la complete con su respuesta. Lo que la mediadora en cuestión propone es que después de leer este libro, se contesten los siguientes aspectos:

-Estoy aquí (en el mundo) para...

¿Cómo se conecta esa respuesta con lo que es importante para mí?

-Con mis principios. 
-Con mis sueños y esperanzas.

-Con mis herencias.

¿Cómo se teje esto que es importante para mí con lo que quiero para mí; lo que quiero para las otras, los otros...; lo que quiero para el mundo?

Este tipo de reflexiones que dislocan al lector y lo posicionan en un lugar distinto es lo que esta promotora busca con su trabajo con la literacidad.

\section{Escribir desde nuestros corazones ancestrales}

Este trabajo fue realizado en una escuela Montessori en la ciudad de Cuautla, Morelos, dentro de una clase adicional bautizada como "literatura". Trabajan en ella la bibliotecaria de la escuela y una promotora de lectura que laboró muchos años dentro del programa Alas y Raíces de la Secretaría de Cultura. Su tiempo es limitado, solo una hora a la semana con cada grupo. Trabajan un tema nada más durante un año, con todos los grupos de la escuela, desde preescolar hasta preparatoria. En este ciclo escolar se aprovechó que 2019 fue declarado como el año de las lenguas indígenas para trabajar con ellas. Su proyecto se llamó "El año en que leímos literatura indígena, conocimos la cosmovisión de los pueblos originarios y escribimos desde nuestros corazones ancestrales". Así lo describe la promotora:

Iniciamos trabajando con las lenguas indígenas, pero una cosa llevó a otra y terminamos indagando profundamente sobre los mitos originarios, lo cual, a su vez, nos llevó a hablar sobre su propio origen (el de los alumnos). No todos estaban entusiasmados al principio, pero como es un proyecto continuo, hubo oportunidad de relacionarlo con muchos otros temas, como el cosmos, la ecología, las plantas y las tradiciones herbolarias de la comunidad, etc. No nos aferramos al programa oficial, y eso es bueno porque nos da oportunidad de "recalcular" según los intereses de los chicos, como vayamos sintiendo la vibra y hacia dónde están inclinándose más. Si ellos se clavan con un tema, nosotros proponemos caminos para explorar por ahí, así que aunque mi compañera y yo desarrollamos el temario, nos guiamos mucho por lo que vemos que los niños disfrutan y necesitan.

Al principio no se evaluaba, pero cuando las directoras vieron que nuestra clase se vinculaba con casi todas las materias y que se generaban problemas cognitivos que concatenaban lo que se veía aisladamente en otras materias, decidieron apoyar la iniciativa dándole un valor en la boleta. Nuestra clase se trata de trabajar con el lenguaje, y de ahí que trate, por obvias conexiones, con el desarrollo del pensamiento, porque hablar y pensar son (o deberían ser) acciones íntimamente relacionadas.

Creo que el éxito está en conectar temas, y sobre todo en no estar saltando de un tema a otro, y solo analizarlo de manera superficial. En realidad, vemos un tema todo el año -aparentemente- pero desde muy variadas perspectivas, lo cual les da oportunidad a los alumnos de tomar una postura personal muy bien argumentada al final del ciclo escolar.

Nuestra esperanza es que se lleven un buen recuerdo de estas experiencias de investigación para que en un futuro también sepan hacer lo mismo con cualquier tema que decidan investigar.

Considero que el rol que juega el docente es crucial, porque aunque damos libertad de acción, tenemos que señalar el rumbo, hacer las preguntas adecuadas para seguir creciendo y avanzando. Si el docente no tiene un objetivo claro, no va a saber conducir adecuadamente. Es mucho trabajo, lo reconozco, pero vale la pena cuando observas las caras de sorpresa cuando los alumnos comprenden o hacen conexiones, cuando tienen 
epifanías. Nosotras, por nuestra cuenta, también las tenemos, porque aunque sabemos a dónde queremos llegar, el camino siempre es luminoso, gracias a las preguntas y las miradas de nuestros alumnos.

\section{¿Libertad de cátedra?}

La maestra Rosalía compartió una experiencia en la que compara dos instituciones de educación media superior distintas, ambas particulares, en las cuales estaba trabajando a la par; tenía a su cargo la materia de Metodología de la investigación, con distintos nombres. Las dos instituciones se autodenominan constructivistas y están basadas en las competencias para la vida.

Durante la cuarentena, cuando nadie sabía muy bien cómo reaccionar, fue aprendiendo en el camino. Su intención era repetir el mismo programa en ambas instituciones para no tener doble carga de trabajo. No pudo hacerlo. En una de las dos instituciones, la dirección vertical impidió que ella fuera modificando su práctica conforme a las necesidades de sus alumnos. Le comentaron: "Las metas están establecidas desde hace ya varios años y más en este momento, no es posible improvisar".

En ambas instituciones le dieron cursos para trabajar a distancia. En una le recomendaron que tomara las herramientas con las que se sintiera más cómoda y, en la otra, la clase de capacitación para docentes fue una instrucción con los pasos totalmente establecidos, en los cuales la instructora repitió una veintena de veces "así es el proceso de manera indiscutible". Los maestros intentaban hacerle ver que algunas fórmulas no aplicaban para su materia y ella solo contestaba que, si no se veían reflejados estos puntos en la planeación, la clase se tomaría como no impartida y, por tanto, no la pagarían. Ese curso la hizo sentir humillada, silenciada y desmotivada. Todo al mismo tiempo. Además, se dio cuenta de que su propósito personal, que no institucional, de desarrollar la literacidad crítica fracasaría, pues no podría responder a las dudas auténticas de sus alumnos ni enriquecer su clase con sus conocimientos y experiencias personales.

En la segunda institución les dieron la misma capacitación para dar las clases a distancia. Ahí la propuesta fue que tomaran las clases virtuales para conocer los recursos que tenían a su disposición y que aplicaran las que consideraran útiles para sus alumnos. La instructora inició con el siguiente discurso:

Les daremos estas herramientas, pero recuerden siempre que la didáctica mata a la tecnología. Esto que les vamos a dar son solo herramientas, pero lo que hará que su clase valga la pena o no es el "coco" que le van a poner a sus clases para que sus alumnos aprendan y se involucren en el proceso. Eso no cambia nunca, independiente de si la modalidad es virtual o presencial.

Los resultados fueron altamente contrastantes. En la escuela de prácticas transmisivas y verticales, los productos finales fueron escuetos, un "copia y pega" de trabajos obtenidos en internet, y la evaluación general del curso fue que, "como siempre", estas clases son de relleno con muy poca aplicación en la vida real.

Los productos finales de la escuela con apertura y flexibilidad fueron diversos, personalizados y adecuados a las posibilidades de accesibilidad y recursos de cada alumno. Los comentarios finales de los alumnos giraron en torno a que el cambio a 
clases virtuales culminó en un aprendizaje no solo de los métodos de investigación, sino también del uso de tecnologías y de formas diversas de convivir y comunicarse a pesar del distanciamiento social.

\section{ANÁLISIS DE LOS CASOS}

En los casos podemos encontrar reflejados varios aspectos a los que alude la literacidad crítica:

- Los maestros crecen y se desarrollan a partir de su práctica docente. La más contundente en este sentido es Clara, quien afirma: "Es mucho trabajo, lo reconozco, pero vale la pena cuando observas las caras de sorpresa cuando los alumnos comprenden o hacen conexiones, cuando tienen epifanías. Nosotras, por nuestra cuenta, también las tenemos, porque, aunque sabemos a dónde queremos llegar, el camino siempre es luminoso, gracias a las preguntas y las miradas de nuestros alumnos".

-Edith lo lleva al extremo de exigir al maestro que ame lo que enseñe.

-Se lee el mundo de manera crítica. El ejemplo del profesor Armando, cuando hace reflexionar a sus alumnos sobre su lugar en el universo, cuando les hace ver que todo es relativo, que pueden ser tan pequeños o insignificantes respecto al todo, pero que, al mismo tiempo, sus acciones pueden significar un gran cambio en la vida de las personas que les rodean, y que más vale pensar en las decisiones propias porque pueden ser generadoras de cambios importantes.

-Se identifican, analizan y critican las ideologías que hay detrás de las prácticas y los contenidos didácticos. Otra vez, Armando expresa casi de manera literal las palabras de Cassany, "leer detrás de las líneas”, y de modo más sutil lo refieren Elena, cuando habla de la valoración de las obras de arte, y Edith, cuando analiza los poemas con los que trabaja.

-Los alumnos se transforman a sí mismos y se asumen como sujetos históricos. Clara narra cómo los alumnos se van conectando con las lenguas indígenas, y pasan de estudiar el tema como algo distante a encontrarse inmersos en él, pues descubren que sus raíces, sus tradiciones y hasta su nombre provienen de ellas, y que, sin saberlo, han conformado desde siempre su identidad.

-Se participa en el mundo para su construcción y transformación. Armando lo puntualiza en forma específica; Edith lo incluye como parte de sus reflexiones en la actividad de lectura; y Clara lo utiliza como el centro de todo su proyecto.

- Cuando existe una comunidad para llevar a cabo un trabajo de literacidad crítica, el trabajo rinde frutos. Esto lo podemos ver reflejado en las palabras de Clara, de Elena y de Rosalía; gracias a que su trabajo es compartido con los colegas y alumnos de manera colegiada, sus proyectos han sido exitosos. 


\section{CONCLUSIONES}

Los casos estudiados llevan a afirmar que es posible desarrollar la literacidad crítica en ramas disciplinares distintas a la enseñanza de la lengua, por las razonas expuestas. Al conocer las experiencias presentadas y los buenos resultados de estos alumnos en su desempeño posterior como alumnos universitarios, sostenemos que la literacidad crítica es un enfoque que eleva en gran medida las posibilidades de crecimiento personal, académico y laboral de los alumnos, pues sus ventajas se pueden observar en el desarrollo de:

-Una identidad asumida y consciente.

-El ámbito académico de los alumnos y, por lo tanto, en el nivel académico de la institución que lo imparte.

- La sociedad que está conformada por personas letradas críticamente que construyen su destino de manera colectiva y corresponsable.

Para lograr que la literacidad crítica se establezca como un enfoque educativo de manera global, habrá que asumir las siguientes premisas:

\section{El alumno tiene que estar al centro de su proceso de aprendizaje}

Cada persona tiene que llevar a cabo el arduo trabajo de pensar. El alumno al que se aspira cuando se trabaja con literacidad crítica es uno que indague, conecte y mantenga un estado de duda permanente. Solo así sus conocimientos serán realmente suyos. Es necesario compartir los procesos educativos con los alumnos, aunque se sacrifique un poco el resultado (Hernández, 2016).

\section{La escuela funciona como un laboratorio experimental}

En realidad, no podemos -ni debemos- esperar que los alumnos que egresan de un bachillerato dominen ninguna de las disciplinas que estudiaron, pues apenas se introdujeron en ellas. Es importante que adquieran un bagaje cultural básico, pero lo que en verdad les va a ayudar tanto en estudios posteriores como en su propia vida es el desarrollo de su proceso cognitivo. Si los docentes desean que sus alumnos lleguen a ser miembros activos de su comunidad académica, que aporten además de ser consumidores, tienen que compartir el proceso y trabajar su metacognición, aparte de su compromiso. David Perkins lo resume en la siguiente idea: "En este mundo complejo, las mejores mentes piensan sobre y con lo que saben, y seguramente serán capaces de darle sentido y están mejor preparadas para compartir nuevas ideas significativas en la conversación global" (Perkins, citado en Church et al., 2011, p. 15, cursivas nuestras). En este sentido, el papel del profesor es de mediador y desarrollador de perspectivas (Bachillerato Internacional, s...., p. 3).

\section{El trabajo educativo es una labor colegiada}

Para empezar, hay que descartar la idea de que la literacidad crítica es cuestión del encargado de la clase de lengua. Se entiende que ser crítico implica una actitud general hacia el conocimiento y el aprendizaje; no está circunscrito a una materia. 
En este sentido, se necesita un ambiente considerable de libertad en el que todos los maestros puedan expresarse, crear y criticar e invitar a sus alumnos a hacerlo. Es un asunto nodal que los maestros tengan ellos mismos un alto nivel de pensamiento y literacidad crítica, porque nadie puede dar lo que no tiene. Pongamos un ejemplo de una propuesta en la cual la literacidad crítica es central: el sistema educativo de Finlandia, que propone lo siguiente:

Una vez que los maestros han sido contratados y están en las aulas, tienen gran responsabilidad. Con un capital humano de tan alta calidad, la gestión escolar se puede realizar de manera diferente. El país no cuenta con inspectores o supervisores de aula. En su lugar, los directores actúan como líderes pedagógicos y, en vez de controlar a los maestros, confían en ellos como profesionales con autonomía y responsables del proceso de enseñanza/aprendizaje. Se alienta a los maestros a trabajar en estrecha colaboración con sus colegas, asesorándose y aconsejándose constantemente entre ellos. Si bien los maestros finlandeses deben seguir el plan de estudios nacional (que se centra en el estudiante y proporciona el marco general y los objetivos de aprendizaje), tienen autonomía para implementarlo (Saavedra, Alasuutari y Gutiérrez, 2019, p. 1).

En otras palabras, las estructuras verticales no combinan con la literacidad crítica, pues en ellas se proporcionan líneas claras de autoridad y una cadena rígida de control que, aunque puede conducir a una alta eficiencia de operación a partir de una supervisión cercana, debilita el sentido de pertenencia de los subordinados, quienes nunca asumirán el proyecto como suyo; mucho menos implicarán a su persona en él. Hay un desequilibrio cuando se actúa de un modo (prescriptivamente) y se exige lo contrario (creatividad y decisión libre).

Para que todos los miembros de una comunidad practiquen una literacidad crítica, es necesario que existan foros y que su voz sea escuchada por los de arriba, los de junto y los de debajo de ellos, tal como lo proponen el Unicef, muchas escuelas que trabajan metodologías activas (caso de Clara) y también el Bachillerato Internacional, de cuyo trabajo ya hemos analizado un ejemplo.

\section{El docente tiene que estar convencido de las bondades de la literacidad crítica y no imponérsele}

La literacidad crítica, como casi toda actividad humana, no se lleva a cabo por decreto ni por imposición. No es cuestión de nombrarla para que inicie una nueva forma de enseñar (ver caso de Rosalía). Aurora y Susana comentaron cómo los maestros son educados para obedecer las órdenes que vienen "de arriba", y para reproducir los planes y programas tal como a ellos les llegan. El que logra esas metas se le reconoce como buen maestro, por eso es tan difícil que se atrevan a innovar, a modificar los planes para adecuarlos a su realidad. Esto va en contra de lo que plantea el enfoque, y los maestros tienen que contar con la capacitación necesaria, así como con el respaldo de su institución para darse la oportunidad de soltar las riendas y compartir la capacidad de decisión y rumbo entre sus alumnos. Si al maestro no se le da el espacio para tomar sus decisiones, cometer sus propios ensayos y errores, él tampoco será capaz de enseñar de esa manera. Maestros controlados tenderán a ser maestros controladores. Maestros proactivos, sin duda, podrán tener más fácilmente alumnos activos y críticos. Justo como se ve en el caso de Rosalía. 
Se tiene que estar dispuesto a trabajar en la incertidumbre y la flexibilidad

Hay que estar dispuesto a recibir resultados distintos; no estandarizados. La literacidad crítica se distancia de lo fijo, de lo establecido. No solo en los productos que se obtienen de ella, sino desde su origen, desde la planeación que se va modificando según las circunstancias y los contextos específicos. Esto puede ser más difícil de practicar de lo que se escucha, pues, al compartir la voz y las decisiones, el plan establecido puede desviarse de lo determinado, a veces bastante. La literacidad crítica no es inocente, y puede ser hasta peligrosa, y esto puede hacer que los maestros se sientan temerosos de soltar, alejarse del programa, decidirse a improvisar o a modificar según vayan ocurriendo las cosas. También puede causar estrés permitir que los alumnos elaboren sus propias preguntas, porque puede ser que no contemos con las respuestas, y lo peor, ¿qué tal si se atreven alguna vez a desafiar lo que nosotros los docentes afirmamos?

\section{PARA CERRAR}

Lo anterior nos lleva a concluir que la literacidad nos hace seres más responsables o, por lo menos, nos quita de las manos la excusa de la ignorancia. La literacidad crítica nos hace comprometernos con nuestro destino y, en consecuencia, con todos aquellos sobre los que tenemos influencia, pues la literacidad crítica tiene un fin eminentemente social.

Así, concluimos que la literacidad crítica ayuda a incrementar las posibilidades de éxito del alumnado en cualquier contexto, pues el enfoque pretende que el sujeto sea capaz de decidir sobre su vida y el desarrollo del mundo. Por tanto, las posibilidades de que se titulen con éxito de su carrera serán mucho mayores, además de que disfrutarán y comprenderán mucho más el trayecto dentro de las aulas universitarias. Estamos a favor de hacer de la literacidad crítica una práctica cotidiana, pues es mejor tener un sentido que ninguno; es mejor ser dueño de las propias decisiones que actuar en reacción a lo que los otros imponen. Es mucho más digno ser el creador del propio destino que una marioneta de quienes lo diseñan para nosotros.

\section{REFERENCIAS BIBLIOGRÁFICAS}

Bachillerato Internacional (s.f.). El estilo de enseñanza del IB. Recuperado de https://www.ibo.org/es/benefits-of-the-ib/the-ib-teaching-style/

Cassany, D. (2006). Tras las líneas. México: Anagrama.

Church, M. et al. (2011). Making thinking visible. Nueva York: Jossey-Bass.

De Grasse Tyson, N. (2019). Scientific thinking and communication masterclass. Recuperado de https://www.masterclass.com/classes/neil-degrasse-tyson-teaches-scientific-thinking-and-communication/chapters/inspire-curiosity-in-your-audience

Elbruch, W. (2005). La gran pregunta. México: Ediciones Tecolote.

Freire, P. (2011). La educación como práctica de la libertad (25 edición). México: Siglo XXI.

Freire, P. (2008). Miedo y osadía. La cotidianidad del docente que se arriesga a practicar una pedagogía transformadora. México: Siglo XXI. 
Freire, P. (1970). Pedagogía del oprimido. México: Siglo XXI.

Hernández, G. (2016). Literacidad académica. México: UAM.

Hernández, G. y Quesada, R. (2020). La lectura y la escritura universitarias como herramientas para transformar el pensamiento. Revista Didac, núm. 75, enero-junio, pp. 40-47.

Larrosa, J. (2003). La experiencia de la lectura. Estudios sobre literatura y formación. México: FCE.

Nussbaum, M. (2008). Cultivating humanity: A classical defense of reform in liberal education. EUA: Harvard University Press.

Saavedra, J., Alasuutari, H. y Gutiérrez, M. (2019). Los maestros y la confianza, los pilares del sistema educativo de Finlandia. Banco Mundial Blogs. Recuperado de https://blogs.worldbank.org/es/education/los-maestros-y-la-confianza-los-pilares-del-sistema-educativo-de-finlandia

SEP (2018). Aprendizajes clave para la educación integral. México.

Unicef (2019). Elementos críticos para la transmisión hacia las habilidades para la vida: desmitificando los conceptos. Nueva Delhi.

Vázquez, V. (2017). Critical literacy. Oxford Research Encylcopedias. https:// doi.org/10.1093/acrefore/9780190264093.013.20 